\title{
A DIGITAL CURRENT CONTROLLER FOR A SINGLE PHASE GRID CONNECTED PHOTOVOLTAIC BASED INVERTER
}

\author{
Raj Kiran B \\ Assistant Professor \\ Department of Electrical Engineering, \\ Mewar University, Chittorgarh, Rajasthan
}

\begin{abstract}
A current controller for a single phase grid tied PV inverter is proposed in this paper. This controller is used for regulating the efficient exchange of power between the single phase grid and the PV inverter. The control method uses Direct-Quadrature (DQ) transformation for controlling the inverter output current according to any change in the load. With this transformation, since the steady state current components are having DC values PI controllers can be employed easily. This digital controller model has been simulated in MATLAB/Simulink environment.
\end{abstract}

Keywords-PV array; Single Phase Full Bridge Inverter; dc-dc converters; Sinsoidal PWM technique; Digital Controller; Current Controller; DQ Tranformation; PI controller.

\section{INTRODUCTION}

Research in renewable energy systems is increasing day by day. One of the main reasons behind this is the low environmental impact of this renewable energy system as mentioned in Michael E. Ropp et.al. (2009). When we consider about energy resources like thermal, nuclear, diesel etc. they will cause environmental problems like harmful gas emission and green house effect. These environmental issues are really very challenging for the existence of our world.

Among the various renewable energy resources existing today, the researchers are mainly focusing on photovoltaic (PV) systems and wind energy systems as discussed in Aslain Ovono Zué et al. (2006), K.Sakthivel et al. (2019). Out of this PV systems are gaining importance in worldwide. This is because of its reliability, reasonable cost of energy production, less environmental impact and it can support microgrid systems. One of the other advantages which should be much more focused is that PV systems can be used both as a standalone system and as a grid connected system. With standalone PV system, energy can be supplied to a consumer without any grid connection. This system is mainly used in regions where there is no grid electricity availability. As Indranil Bhattacharya et al. (2010) shown, If we consider the grid connected PV systems as its name implies they have some sort of connection to the grid, i.e. they can supply the surplus power available back to the grid.

While dealing with these many advantages, there are some disadvantages also existing in PV energy systems. Major problems related to PV systems are high installation cost, nonuniform ability in the energy production, various energy conversions are required for meeting the load requirements and also due to the non-linear characteristic behaviour of PV panels, it also requires maximum power point tracking (MPPT) methods which are mainly employed along with the $\mathrm{dc}$ to $\mathrm{dc}$ or dc to ac conversion stages as discussed in Damrong Amorndechaphon et al. (2008).

When PV systems are used as grid tied PV systems, there are many things that should be taken into the account. Main among them is that a good controller should be there for regulating the power flow between the PV fed inverter and the grid. This is required for reactive and active power flow control between the grid and the inverter connected with the load as described in Djilali Hamza et. al (2013). Here in this paper a digital current controller is used for regulating the power flow. As shown in Higang Liang et al. (2010) Current controller is used because current is the quantity which is easily dependent on the load variation. Here in DQ controller, various transformations are carried out and PI controllers are used to regulate the power exchange.

\section{SINGLE PHASE FULL BRIDGE INVETER}

A single phase inverter is a power electronic interface circuit that converts a fixed dc to a single phase ac at desired frequency. It consists of two legs with two switches each. No two switches in same leg should energize simultaneously. In order to operate inverter we can use PWM techniques. Fig.1. shows the circuit configuration of a single phase full bridge inverter.

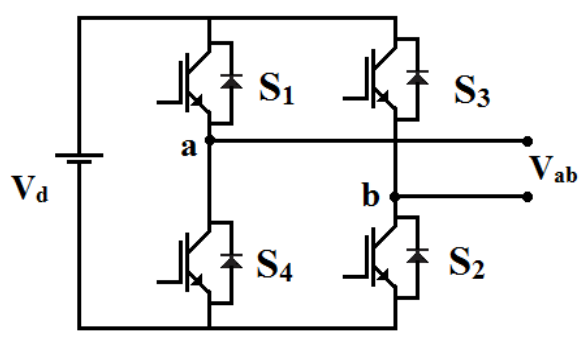




\section{SIMULATION RESULTS}

The most common and popular technique for generating true sine wave is Pulse Width Modulation (PWM). Sinusoidal Pulse Width Modulation is the best technique for this. Here we are going for unipolar PWM technique. In unipolar scheme, the switching devices in one leg are turned on or off based on the comparison of the modulation signal with a high frequency triangular waveform. In unipolar switching, the output voltage polarity remains positive or negative for a half cycle period. Thus output takes three voltage levels $+V_{d}, 0$ and $-V_{d}$

\section{Single Phase DQ TRANSFORM}

Single phase DQ transform is a synchronous reference frame transformation in which a pair of orthogonal quantities in stationary frame is transformed to rotating frame. As discussed earlier, in this paper a current controller is used for the power flow regulation. For this controller we use the DQ transform and then using a discrete PI controller the proper regulation is obtained.

DQ transform can also be obtained by initially transforming to $\alpha \beta$ frame and then by rotating it at fundamental frequency. The resultant $D$ and $Q$ vectors in this rotating reference frame will be a constant. This indicates that two orthogonal components are required for the transformation to the synchronous reference frame is shown in B Crowhurst et al. (2010). Inorder to generate one missing orthogonal component various methods are being suggested and these methods are generally termed as fictitious phase generation technique.

In the literature, several fictitious phase generation techniques are mentioned, which includes transport delay, all pass filters, Hilbert transformations and second order generalized integrator (SOGI) methods. Here transport delay method is used for generating fictitious phases and this is used for achieving $\pi / 2$ delay.

Now for transforming a current signal to DQ frame using transport delay method, the actual current signal is denoted as the real current $I_{r}$ and $\pi / 2$ delayed current signal as the imaginary current $\mathrm{I}_{\mathrm{i}}$. The matrix representation of transformation of real and imaginary components to DQ is given below.

$$
I_{d q}=\left[\begin{array}{l}
I_{d} \\
I_{q}
\end{array}\right]=T I_{r i}=\left[\begin{array}{cc}
\sin \omega t & -\cos \omega t \\
\cos \omega t & \sin \omega t
\end{array}\right]\left[\begin{array}{c}
I_{r} \\
I_{i}
\end{array}\right]
$$

Here the original signal's DC component is mapped to the AC signals which are rotating at fundamental frequency in the DQ frame. Thus the presence of DC component will make the steady state error as zero. For transforming back to real and imaginary frame inverse transform is used. The matrix representation for that transformation is shown below.

$$
I_{r i}=\left[\begin{array}{c}
I_{r} \\
I_{i}
\end{array}\right]=T^{-1} I_{d q}=\left[\begin{array}{cc}
\sin \omega t & \cos \omega t \\
\cos \omega t & -\sin \omega t
\end{array}\right]\left[\begin{array}{c}
I_{d} \\
I_{q}
\end{array}\right]
$$

Simulation of DQ current controller is done in MATLAB/Simulink environment. Overall simulink model of the system is given in the Fig. 2. The main parts of this simulink model are grid tied inverter, single phase grid, DQ controller and the load.

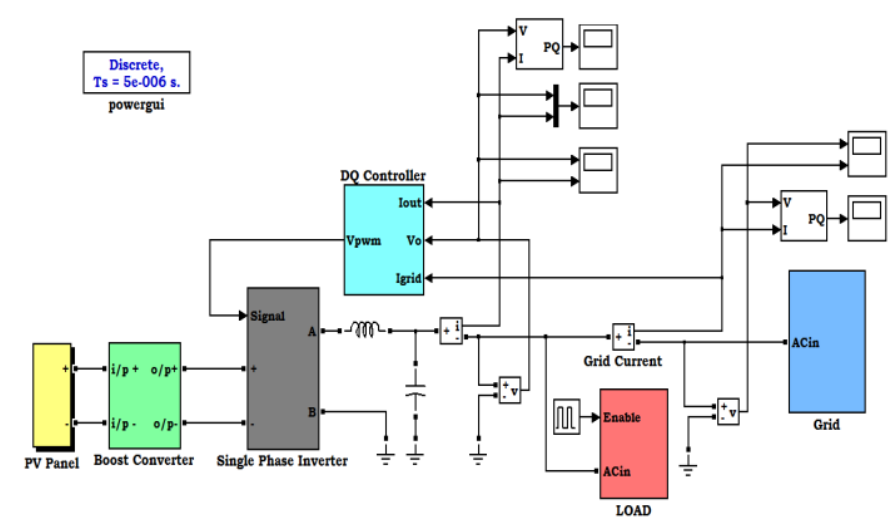

Fig.2. MATLAB/Simulink model of Grid Tied PV fed Inverter

From the simulink model file shown above it can be seen that the load is connected in between the inverter and the single phase grid. The main aim of this DQ controller is to ensure that as long as the PV power is available it should be taken for supplying to the load. Whenever the PV power is not available then only the load should take power from the utility grid. Here R-Load of 1000W and RL-Load of 1000W, 500VAR is assumed as the two scenarios. During the simulation for first 0.3 secs R-Load operate and for next 0.3 secs RL-Load will operate. Thus we can see that during these load variations this DQ controller will generate suitable reference waveform for the inverter sinusoidal PWM technique and thus ensure that the power is fed from the inverter to the load and not from the grid to the load. Fig.3. shows the MATLAB/Simulink model for the DQ controller.

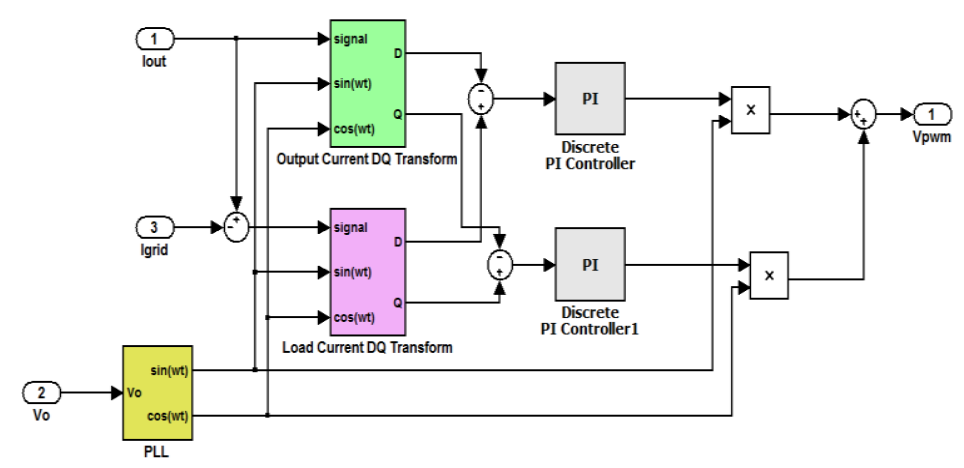

Fig. 3. MATLAB/Simulink Model of DQ Controller

The DQ control circuit includes PLL, DQ transform blocks, D and Q PI controllers and also inverse DQ transformation.PLL is used for the sine and cosine reference generation which are used in both DQ transformation and 
inverse DQ transformation. Here inverter output current is transformed into DQ. Then the load current is determined by subtracting grid current from the inverter current and then it is also transformed do DQ rotating reference frame.

After these DQ transformations, load current is used as the command signal and then inverter output current is subtracted from it. This will generate D and Q error signals and then they are passed into discrete PI controller. The main function of this PI controller is to eliminate the error between the load current and the inverter output current.

Fig.4.shows the inverter output voltage and current on the same scope. It is clear that both the voltage and current waveforms are having same frequency and are in phase when R-Load operates and also there is a phase difference while RLLoad is operating.

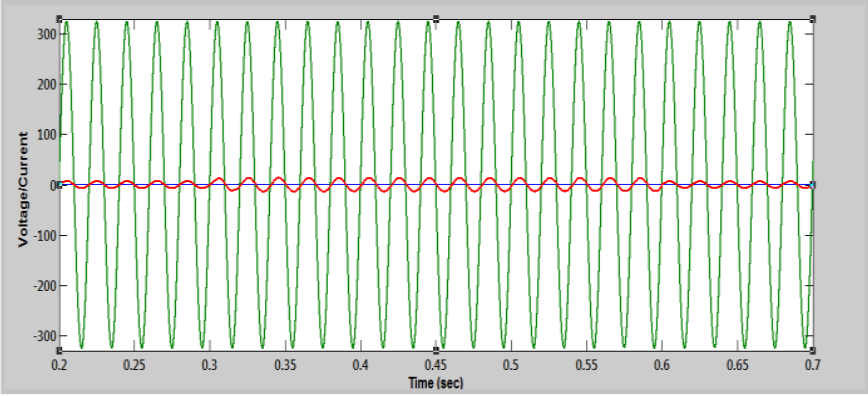

Fig. 4.The inverter output voltage and current

Also Fig. 5 and Fig. 6.shows the inverter output voltage and output current waveforms respectively. It can be seen that in the output current waveform the current value is increased when the load is switched from R-Load to RL-Load at $0.3 \mathrm{secs}$.

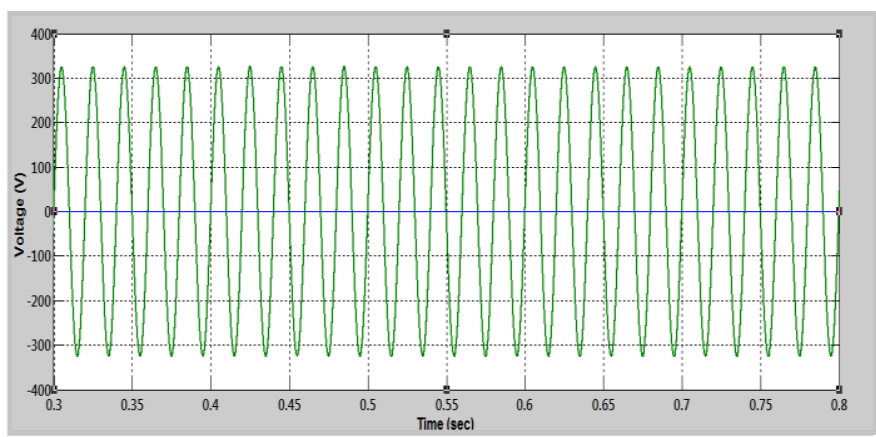

Fig.5 The inverter output voltage

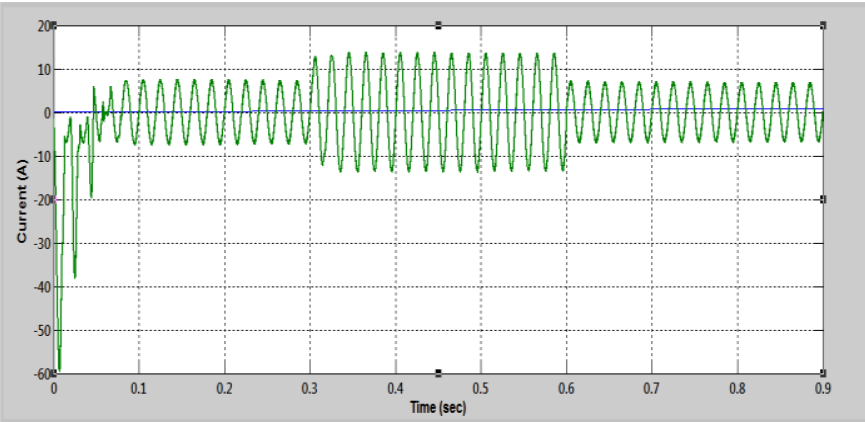

Fig.6 The inverter output current

With the help of the DQ controller it is possible for regulating the power flow between PV powered inverter and single phase grid both connected to a common load. In the simulation, the load variation is incorporated by switching RLoad for first 0.3 secs and then RL-Load for next 0.3secs. Fig.7. shows the power output from the inverter. It can be seen that for the first $0.3 \mathrm{secs}$ the power drawn from the inverter by the load is about $1000 \mathrm{~W}$ and for the next 0.3 to 0.6 secs power by load is $1000 \mathrm{~W}$ and 500VAR.Like this the cycle repeats. Thus it can be clearly seen that using this DQ current controller no power is taken from the grid. Power required for the load can be supplied from the PV fed grid tied inverter.

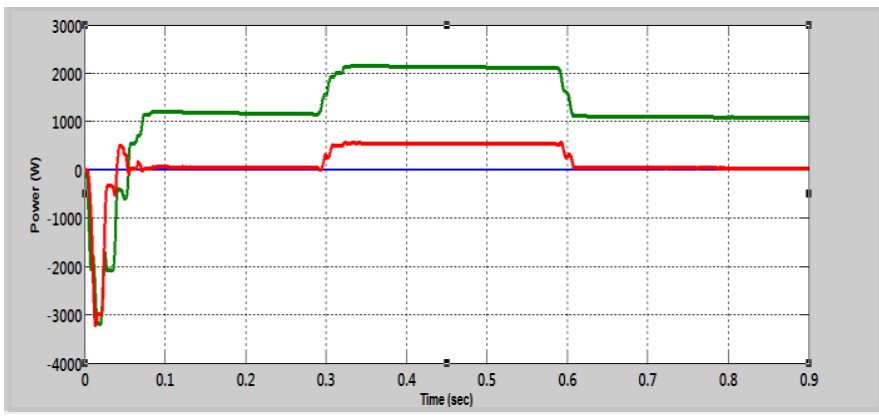

Fig. 7 Active and reactive power flow from inverter

Fig. 8 and Fig. 9 shows the single phase grid voltage and grid current respectively. The grid voltage is maintained at $230 \mathrm{~V}$. It is also seen that the grid current is almost zero throughout the operation. Thus it can also be inferred that the net power transfer from the grid is also almost zero.

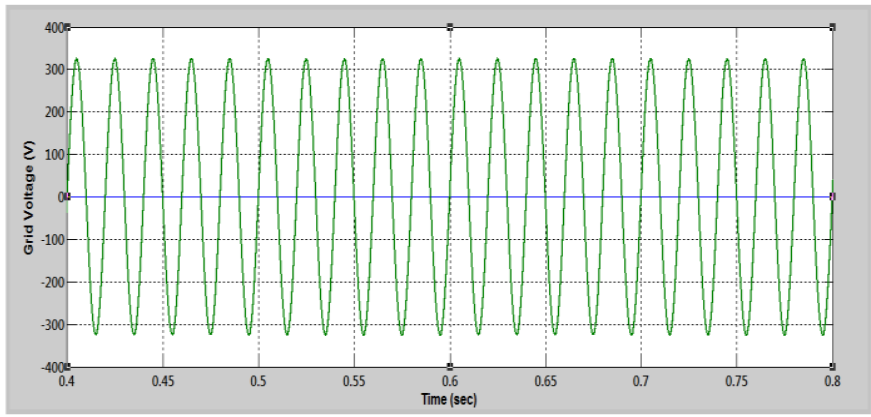

Fig. 8 Single phase grid voltage

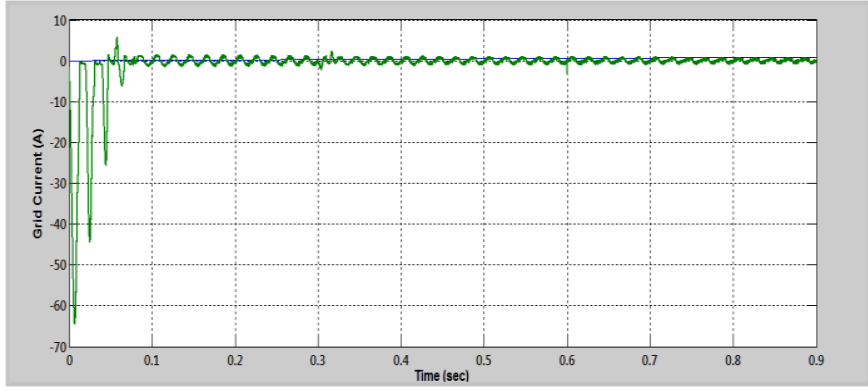

Fig. 9 Single phase grid current 
Hence, it can be clearly noticed that the power drawn by the load from the single phase grid is almost zero. Fig.10. shows the active and reactive power flow between the load and the grid. From the waveform it can be seen that active and reactive power drawn from the grid by both R-Load and RL-Load are almost in the range of zero. So with these simulation results, it can be inferred that with the proposed controller an efficient power transfer can be obtained. Here in the controller with various transformations like DQ and inverse DQ transformations and also with discrete PI controllers it was able to achieve an efficient power regulation between the grid tied inverter and single phase grid both connected with a common load.

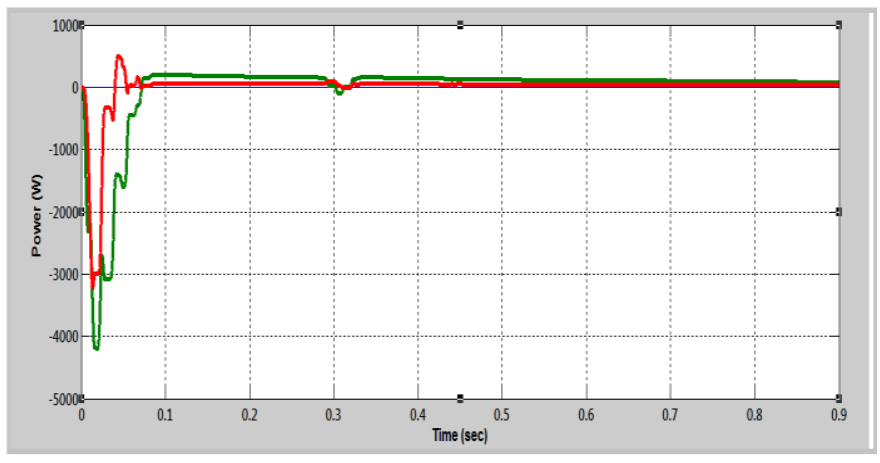

Fig. 10 Active and reactive power flow from grid

\section{RESULTS AND OBSERVATIONS}

Simulation of a digital DQ current controller for a grid tied inverter was done in MATLAB/Simulink environment. The various simulation waveforms are obtained.

From the simulation carried out it is clear that by employing a suitable controller a very excellent and efficient power regulation can be obtained. Here the PV fed inverter and the single phase grid is connected with a common load. This load itself is switched to R-Load for sometimes and then RL-Load for sometimes. Using DQ current controller it was possible that the power for the load was totally being fed from the grid tied inverter and at the same time it also ensures that no power is drawn by the load from the single phase grid side.

\section{CONCLUSION}

Photovoltaic grid tied inverter are gaining more importance nowadays. The main reason behind this is the energy crisis and also its environmental friendly power generation when compared with other power generation methods existing now. The main need for the controller in a grid tied inverter is to regulate the power flow from the inverter to the load and from the grid to the load. Here the simulation of a digital current controller in MATLAB/Simulink environment is carried out. With the proposed DQ current controller an efficient power exchange is achieved between the inverter and the grid.

\section{ACKNOWLEDGEMENT}

This research work was done during my PG at VIT University, Chennai. I thank institution management for providing all the facilities and all faculty members of university who provided insight and expertise that greatly assisted the research.

\section{REFERENCES}

[1] Michael E. Ropp and Sigifredo Gonzalez (2009), "Development of a Matlab/ Simulink model of a singlephase grid-connected photovoltaic System," IEEE transactions on energy conversion, 2009 IEEE

[2] Aslain Ovono Zué, Ambrish Chandra (2006) "Simulation and Stability Analysis of a $100 \mathrm{~kW}$ Grid Connected LCL Photovoltaic Inverter for Industry," 2006 IEEE

[3] Indranil Bhattacharya, Yuhang Deng, Simon Y.Foo (2010) "Active Filters for Harmonics Elimination in Solar Photovoltaic Grid-Connected and Stand-Alone Systems", Florida State University, Tallahassee, Florida 32310, USA, 2nd Asia Symposium on Quality Electronic Design, 2010 IEEE.

[4] Damrong Amorndechaphon and Suttichai (2008), "An Improved Soft-Switching Single-Phase Inverter for Small Grid-Connected PV-System," Department of Electrical Engineering Chiangmai University, 2008 IEEE.

[5] Djilali Hamza, Mei Qiu and Praveen H. Jain (2013) “ Application And Stability Analysis Of A Novel Digital Active EMI Filter Used In A Grid Tied PV Microinverter Module" IEEE Transaction on Power electronics June 2013.

[6] Higang Liang, Larry Alesi, Xiaohu Zhou, Alex Q. Huang (2010) "Digital Controller Development for GridTied Photovoltaic Inverter with Model Based Technique"2010 IEEE.

[7] B. Crowhurst, E.F. El- Saadany, L. El Chaar and L.A. Lamont (2010) "Single-Phase Grid-Tie Inverter Control Using DQ Transform for Active and Reactive Load Power Compensation" PECon 2010, Malaysia.

[8] I. H. Atlas and A.M. Shara (2007),: A Photovoltaic Array Simulation Model for Matlab-Simulink GUI Environment, Karadeniz Technical University, Trabzon, Turkey and University of New Brunswick, Fredericton, Canada. 2007 IEEE.

[9] Zhang.R. Cardinal, M (2002), “A grid simulator with control of single-phase power converters in D-Q rotating frame", Power Electronics Specialists Conference, 2002.

[10] M.H.Rashid; Power Electronics: Circuits, Devices and Applications.

[11] Moien A.Omar, Marwan M. Mahmoud (2019), "Design and Simulation of a PV System Operating in Grid- 
Connected and Stand-Alone Modes for Areas of Daily Grid Blackouts", International Journal of Photoenergy

[12] K.Sakthivel, V.Jayalakshmi, G.Rajakumari (2019), "Modeling and Simulation of a GRID-TIED Solar PV System", International Journal of Recent Technology and Engineering (IJRTE), ISSN: 2277-3878, Volume-7 Issue-6S2, April 2019. 